\title{
Ulcera eosinofílica de la lengua
}

Detgado W, Funes I. Uleera eosinofilica de la lengua. Rev Estomatol Herediama 2003: 13(1-2) $36-39$.

RESUMEN

Se revisa la literatura y se discuten las características elínicas. histologicas, diagnóstico y evolución de un caso de úlcera eosinofilica (UE) de la lengua en un paciente de 53 años de edad. cuya presentación clfatica semejaba a un carcinoma epidermoide. Sobre la base de los hallazgos histológicos y la respuesta clinica al procedimiento quinirgico de la totra de biopsia, se plantea La posibilidad, que por lo menos en este ciso, la UE haya resultado, primariamente de una lesión de la pared de los vasos sanguíneos que condujo a ulecración, hemorragia y formación de extensas áreas de fibrina, con la consecuente alteración del proceso de reparación

Palabras clave: đlcera cosinofilica - earcinoma epidermoide - tifeera traumítica - granuloma ulecrativo traumílico con eosinofilia estromal

Easinophilic ulcer of the tongue.

SUMMARY

The literature of eosinophilic uleer (EU) of the oral mucosa is reviewed. The clinical and histological features, as well as, the diagnosis and evolution of a case of cosinophilie ulect of the tongue in a 53 years-old patient mimicking squamous cell carcinoma in preiented. Bissed on the histological findings and the clinic renction to the biopsy surgical procedure for the diaunosis, if is suggested that. al least in this case, the development of the EU could have been piimarily. lesion of the blood vessels that produce uleerntion, hemorrhinge, and fibrin deposits which impair the reparative process.

Keywords: Eosinophilic ulcer - Squamoos cell carcinoma - Traumatic ulcerative - Traumatic ulcerative granuloma with stromil eosinophilia.

\section{Introducción}

La úlcera eosinofílica (UE) es una lesión infrecuente de la mucosa oral cuya característica histológica es la presencia de un infiltrado de eosinófilos en el tejido conectivo. En la literatura inglesa esta entidad ha sido reportada bajo diferentes nombres. En infantes se la ha denominado enfermedad de Riga o de Riga-Fede (1), granuloma sublingual (2) y lesión reparativa de la lengua (3). En adultos se la ha descrito como granuloma traumático (4), granuloma eosinofílico (5), úlcera eosinofílica (6), granuloma eosinofílico traumático (7), granuloma eosinofílico ulcerativo (8) y granuloma ulcerativo traumático con eosinofilia estromal (9).

Si bien la etiología de la UE es desconocida, en la mayoría de los reportes se la ha relacionado con factores traumáticos. En infantes se ha reportado en la cara ventral de la lengua asociada a la presencia de dientes natales y neonatales denominándola usualmente enfermedad de Riga-Fede (1-3) y en adultos se ha atribuido a mordeduras, bordes de dentaduras, retenedores de dentaduras parciales, dientes rotos etc. En muchos casos no se ha podido identificar un agente traumático (9). Aparece principalmente en la lengua y en la zona sublingual pero también ha sido descrita en otras zonas de la boca incluyendo las encías (7). El rango de edad de presentación oscila entre tres días y 92 años (9) Clínicamente se presenta como una úlcera moderadamente dolorosa cuyo tamaño varía desde unos milímetros a varios centímetros $(6,8,9)$, que puede ser confundida con una neoplasia maligna $(10,11)$.

El papel que los eosinófilos tienen en este tipo de ulceraciones no está establecido. Por estudios en animales de experimentación se ha propuesto que los eosinófilos pueden contribuir a la regulación de muchos procesos biológicos que son críticos para una apropiada curación de las heridas debido a que estas células expresan dos citoquinas multifuncionales transformantes del crecimiento, el factor- $\alpha$ $($ TGF- $\alpha$ ) y el factor $\beta 1$ (TGF- $\beta 1$ ) (11).

El TGF- $\alpha$ promueve la migración y proliferación epitelial, además de ser un potente inductor de la angiogénesis (12). El TGF- $\beta 1$ ha sido asociado con la inhibición de la proliferación epitelial (13), la regulación de la inflamación (14) y la producción de matriz extracelular y remodelado de tejido (15).

En un trabajo realizado para determinar si los eosinófilos presentes en úlceras eosinofílicas producían los factores de transformación de crecimiento mencionados se encontró que en 11 de 12 casos estudiados los eosinófilos mostraban muy poco o ninguna expresión de estos factores, lo que sugiere que el retardo en la curación de estas heridas probablemente está relacionada con la falta de síntesis de estos factores por los eosinófilos (16).
Wilson A. Delgado' Italo Funes ${ }^{2}$

'Prolesor dei Departamemo de Meficina. Cingia y Patologia Oent.

Peeiderite de La Enpociafidad de Cinola Oraly Moriotacial.

Facuitad do

Cayotano Heredia
El propósito de este trabajo es presentar los aspectos clínicos, histopatológicos, el diagnóstico diferencial y el manejo de un caso de úlcera eosinofílica de la lengua, así como postular una probable teoría para explicar el fenómeno tisular involucrado.

\section{Reporte de caso}

Paciente varón de 53 años de edad, de profesión chofer, que hace aproximadamente 30 días, cuando comía piña, sintió que se lastimó la punta de la lengua produciéndose una pequeña herida la cual fue aumentando de tamaño acompañado de dolor y leve ardor. Hace diez días el dolor se intensifica por lo que acude a un médico quien le receta ketorolaco y una pasta a base de cortisona para aplicación local. Debido a que no se logra resultados positivos, es referido al servicio de Medicina Oral de la Facultad de Estomatología de UPCH para diagnóstico y tratamiento.

La anamnesis no aporta información que pueda contribuir al diagnóstico de la lesión. No relata antecedentes de enfermedades sistémicas o neoplásicas. Fuma de 10 a 12 cigarrillos diariamente, toma licor esporádicamente, no ha visitado zonas endémicas para hongos ni parásitos y sus funciones biológicas están conservadas. Refiere actividad heterosexual y niega relaciones homosexuales.

El examen clínico muestra un sujeto aparentemente en buen estado de sa- 
lud que presenta, en la mitad izquierda de la punta del dorso de la lengua, una úlcera de forma redondeada de más o menos $2.5 \mathrm{~cm}$ de diámetro cubierta por un material blanco amarillento, con pequeñas áreas hemorrágicas; a la palpación se percibe una masa ligeramente dolorosa de consistencia firme que puede individualizarse de los músculós de la lengua (Fig. 1)

Los diagnósticos clínicos diferenciales planteados fueron: carcinoma epidermoide, úlcera tuberculosa, histoplasmosis, neoplasia benigna ulcerada (probablemente un mioblastoma de células granulares), chancro sifilítico y linfoma. Para establecer el diagnóstico definitivo se tomó una biopsia incisional en forma de cuña. También se so- licitó un hemograma y se prescribió un millón de fenoximetilpenicilina cada 8 horas y ketorolaco condicionado a la presencia de dolor.

\section{Resultados de los exámenes}

El hemograma no reveló ninguna alteración. El examen anátomo-patológico mostró una ulceración cubierta con una gruesa capa de fibrina en cuya superficie se distinguían colonias de gérmenes y levaduras e hifas de cándida (Fig 2). En el tejido conectivo y plano muscular distribuido irregularmente, se observaba un infiltrado mononuclear formado por linfocitos, escasas células plasmáticas e histiocitos. Entre estas células y entre los haces musculares se distinguían cantidades variables de eosinófilos y algunas células cebadas (Fig. 3, 4 y 5). También se podía identificar áreas de necrosis con presencia de polimorfonucleares, focos de hemorragia y coágulos de fibrina que ocluỉan el lumen de pequeños vasos sanguíneos dilatados (Fig. 6). El epitelio del margen de la ulceración mostraba hiperplasia reactiva de clavos epiteliales.

Evolución : A las 48 horas de haber tomado la biopsia el paciente manifestó alivio del dolor y a los cinco días la lesión se había reducido considerablemente de tamaño (Fig. 7). Se prescribió siete días adicionales de antibioticoterapia a base de penicilina. El control a los diez días mostró reparación favorable de la lesión (Fig. 8).

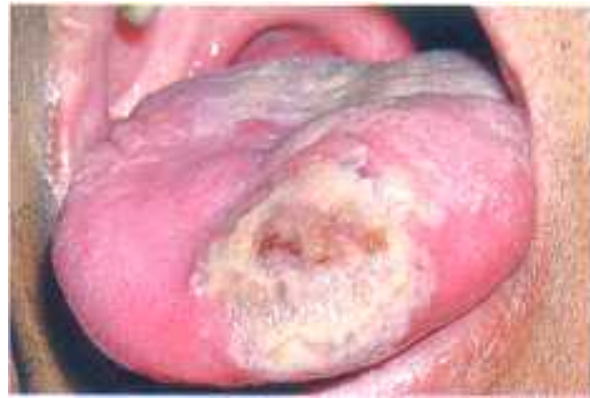

Fig. 1 Ulcera cubierta por pseudomembrana blanquecina y secreción seropurulenta.

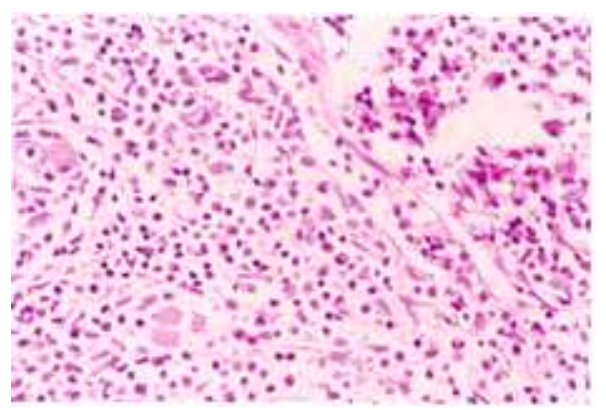

Fig. 4 Infiltrado inflamatorio crónico : linfocitos, algunas células plasmáticas y eosinófilos. H\&E 400X.

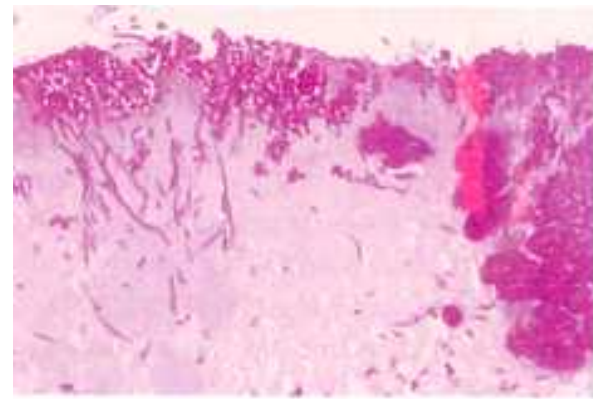

Fig. 2 Superficie de la úlcera. Fibrina infiltrada con levaduras e hifas de cándida y colonias de bacterias. PAS $400 \mathrm{X}$.

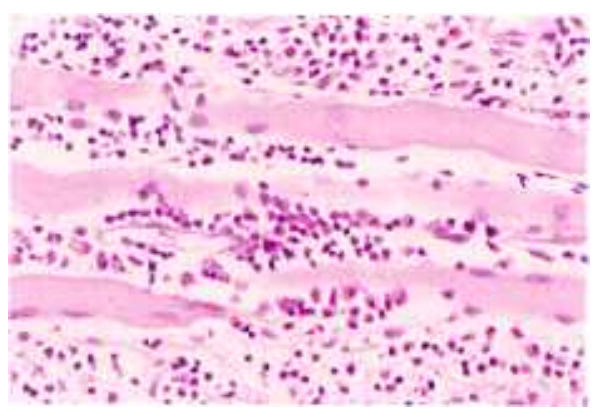

Fig. 5 Infiltrado de linfocitos y abundante cantidad de eosinófilos entre los haces musculares. H\&E $400 \mathrm{X}$.

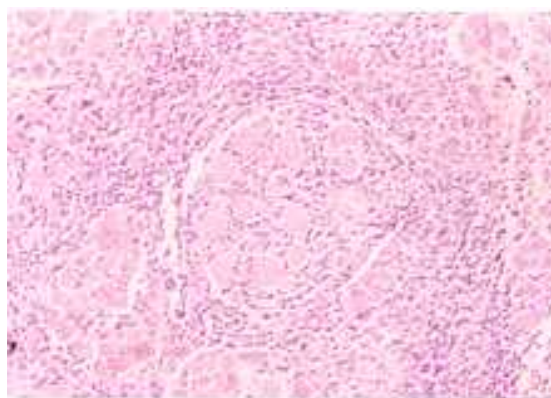

Fig. 3 Infiltrado inflamatorio crónico en el tejido conectivo y entre los haces musculares. $\mathrm{H} \& \mathrm{E} 200 \mathrm{X}$.

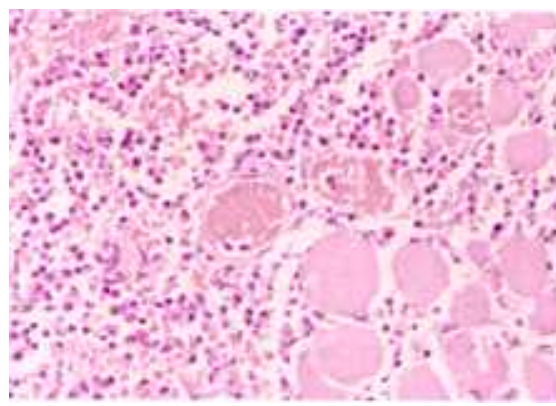

Fig. 6 Congestión vascular, áreas de hemorra gia, infiltrado inflamatorio agudo y crónico. $\mathrm{H} \& \mathrm{E} 400 \mathrm{X}$

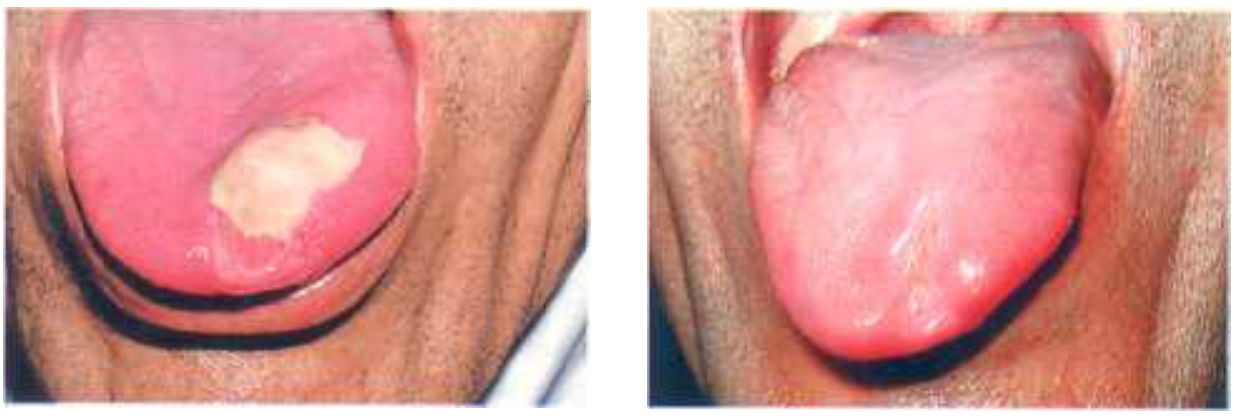




\section{Discusión}

Las úlceras en mucosa oral son lesiones relativamente comunes cuyas características clínicas y etiología son muy variables. Las causas que producen úlceras en la mucosa oral se pueden resumir de la siguientes manera :

1. Trauma físico, químico o térmico

2. Agentes infecciosos (virus, bacterias, hongos, parásitos)

3. Reacciones alérgicas

4. Neoplasias malignas,

6. Enfermedades sistémicas (enfermedades autoinmunes, vasculitis etc.) y

7. Origen desconocido (úlcera eosinofílica, aftas recidivantes).

El caso que reportamos ilustra las características clínicas y evolutivas de una lesión ulcerativa, aparentemente proliferativa, que en corto tiempo había alcanzado $2.5 \mathrm{~cm}$ tamaño, que no había respondido al tratamiento con antibióticos, y cuyo diagnóstico histopatológico correspondió a úlcera eosinofílica. Los diagnósticos diferenciales planteados fueron : carcinoma epidermoide, úlcera tuberculosa, histoplasmosis, neoplasia benigna ulcerada (probablemente un mioblastoma de células granulares), chancro sifilítico y linfoma. Para descartar cualquiera de estas entidades se consideró fundamental la obtención de una biopsia, la que condujo al diagnóstico definitivo de úlcera eosinofílica.

La úlcera eosinofílica de la mucosa oral tanto en infantes, adultos y ancianos ha sido descrita mayormente en la lengua $(6,9,17,20)$, En una serie de 70 casos revisados por Elzay (9), 37 se encontraron en la lengua y la edad de los pacientes estaba entre un mes y 82 años, el tiempo de evolución de las lesiones variaba desde una semana hasta 120 días. Otro autor ha indicado que puede ocurrir en cualquier edad y la duración de la evolución es de 2-9 semanas (18). Si bien la lesión se presenta principalmente en lengua también ha sido reportada en labios (4), encía (7) paladar duro (19) y en otras zonas de la boca (9).

En la mayoría de estudios se postula al trauma como:agente etiológico y de alguna forma esto es respaldado por
Bashkar y Lilly (4) quienes produjeron úlceras eosinofílicas en forma experimental induciendo trauma con forceps en lenguas de ratas. Los cambios histológicos encontrados en el trabajo de estos investigadores fueron similares a las úlceras eosinófilas descritas de la lengua de humanos.

El papel que juegan los eosinófilos en este tipo de ulceraciones, no está establecido. Si bien se conoce que en los modelos de curación de heridas en animales estas células normalmente producen TGF- $\alpha$ y TGF- $\beta 1$ que son importantes en el proceso de curación de heridas, en el caso de las úlceras eosinofílicas de los humanos la síntesis de estos factores no es significativa (16) lo que explicaría el retardo en la curación de este tipo de lesiones.

En el estudio histológico del presente caso, además del infiltrado de eosinófilos merece ser destacado el depósito de grandes cantidades de fibrina y de tapones de coágulos en los vasos sanguíneos. Estos cambios histológicos sugieren la posibilidad de que en este caso primariamente se haya producido daño a la pared de los vasos sanguíneos que condujo a la ulceración, hemorragia y depósitos de fibrina, alteraciones que serían los responsables de la apariencia clínica de la lesión y del retardo en la cicatrización. Sin embargo, se debe señalar que esto no explica la presencia del infiltrado de eosinófilos

Por otro lado la respuesta positiva en la reparación de la úlcera, que se observó después de la toma de la biopsia, favorece una teoría vascular en la generación de la lesión, ya que el acto quirúrgico para obtener una biopsia trae como resultado una respuesta inflamatoria, donde destacan los fenómenos hemodinámicos que conducen a restablecer el proceso de reparación. Esta propuesta explica de alguna manera el fenómeno tisular pero no identifica al agente etiológico, el cual probablemente este relacionado con algún tipo de antígeno bacteriano.

Finalmente, desde el punto de vista clínico es importante destacar que en el presente caso la lesión de mayor trascendencia planteada en el diagnóstico diferencial fue carcinoma epidermoide, por lo que la obtención de una biopsia fue fundamental para establecer el diagnóstico definitivo. En relación con el tratamiento, dados los resultados clínicos post-biopsia consideramos que la administración de antibióticos no fue determinante en la reparación de la lesión.

\section{Referencias}

1. Curt G. Neonatal sublingual traumatic ulceration (Riga-Fede disease). Report of cases. J Dentistry Children. 1966; 63:262-64.

2. Abramson M. Dowrie JO. Sublingual granuloma in infancy (Riga-Fede Disease). J Pediatr 1944; 24: 195-198.

3. Mc Daniel RK, Morano PD. Reparative lesion of the tongue. Oral Surg 1978;45:266-271.

4. Bhaskar SN, Lilly GE. Traumatic granuloma of the tongue (Human and Experimental. Oral Surg 1964; 18:206.218.

5. Welborn JF. Eosinophilic granuloma of the tongue. Report of a Case. J Oral Surg 1966; 24: 1776-179

6. Burgess GH, Mehregan AH, Drinnan AJ. Eosinophilic ulcer of the tongue. Arch Dermatol 1977; 113(5):644-645.

7. Tornes K Bang G. Traumatic granuloma eosinophilic of the Gingiva. Oral Surg Orla Med Oral Pathol 1974; 38(1):99-102.

8. Tang TT, Glicklich M, Hodach AE, Oechler HW, McCreadie SR. Ulcerative eosinophilic granuloma of the tongue. A light- and electron-microscopic study. Am J Clin Pathol 1981;75(3):420-425

9. Elzay RP. Traumatic ulcerative granuloma with stromal eosinophilia (Riga -Fede's disease and traumatic eosinophilic granuloma). Oral Surg Oral Med Oral Pathol 1983; 55(5):497-506.

10. Gopalakrishnan R, Miloro $M$ and Allen CM. Indurated ulceration of the tongue. Oral Surg Oral Med Oral Pathol 1966; 82:119-121.

11. Wong DTW, Donoff RB, Yang J, et al. Sequential expression of transforming growth factors alpha and beta 1 by eosinophils during cutaneous wound healing in the 
hamster. Am J Pathol 1993; 143(1):130-42.

12. Schreiber AB,Winkler ME, Derynck $R$. Transforming growth factor-alpha: a more potent angiogenic mediator than epidermal growth factor. Science 1986; 232 (4755): 1250-3.

13. Tucker RF, Shipley GD, Moses HL, Holley RW. Growth inhibitors fröm BSC-1 cells closely related to platelet type beta transforming growth factor. Science 1984; 226(4675):705-7.

14. Kehrl JH, Wakefield LM, Robert AB, et al. Production of transforming growth factor beta by human T lymphocytes and its potential role in the regulation of $\mathrm{T}$ cell growth. J Exp Med 1986; 163(5):1037-50.

15. Bernard JA, Russette ML, Moses HL. The cell biology of transforming growth factor $\hat{a}$. Biochim Biophy Acta 1990; 1032: 79-87.

16. Elovic AE, Gallagher GT, Kabani S, Galli SJ, Weller PF, Wong DT. Lack of TGF-alpha and TGF-betal synthesis by human esosinophils in chronic oral ulcers. Oral Surg Oral Med Oral Pathol Oral Radiol Endod 1996; 81(6):672-81.
17. Song M, Achten G. Eosinophilic ulcer of the tongue. Arch Dermatol 1973; 108(1):133.

18. Shapiro L. Juhlin EA. Eosinophilic ulcer of the tongue. Report of two cases and review of the literature. Dermatologica 1970; 140(4):242-250

19. Cheng H, Kim NS, Kim YB, Kang WH. Eosinophilic ulcer of the oral mucosa Inter J Dermatol 1998; $37: 432$.

20. Vizcaya L, Nuñez JM, Toranzo JM, Falcon R. Úlcera eosinofílica de la Lengua. (Reporte de un caso clínico) Revista ADM 2003; LX(1): 40-42. 